\title{
A rare finding of mites (Arachnida: Acari: Leeuwenhoekiidae) parasitising a whip spider (Arachnida: Amblypygi: Charinidae)
}

\author{
Thiago Gonçalves-Souza ${ }^{1}$, Alessandro P. L. Giupponi ${ }^{2}$ and Fabio A. Hernandes ${ }^{3}$ \\ ${ }^{1}$ Departamento de Biologia Animal, Instituto de Biologia, Universidade Estadual de Campinas (UNICAMP), Campinas, SP, Brasil; \\ ${ }^{2}$ Laboratório Referência Nacional em Vetores das Riquetsioses, Coleção de Artrópodes Vetores Ápteros de Importância em Saúde \\ das comunidades, Fundação Oswaldo Cruz, Instituto Oswaldo Cruz, Rio de Janeiro, RJ, Brasil; \\ ${ }^{3}$ Universidade Estadual Paulista Júlio de Mesquita Filho, Instituto de Biociências de Rio Claro, Departamento de Zoologia, Bela \\ Vista, Rio Claro, SP, Brasil
}

\begin{abstract}
Twelve larvae of unidentified species of Odontacarus Ewing, 1929 (Acari: Leeuwenhoekiidae) were found parasitising an adult male whip spider Charinus brasilianus Weygoldt (Charinidae) in Santa Teresa, mountainous region of Espírito Santo state, southeastern Brazil. These larvae occurred in the intersegmental membrane of prosoma and legs. This is the first report of ectoparasitic mites infecting a charinid whip spider and the first record of leeuwenhoekiid mites parasitising an invertebrate host. We suggest that future studies are essential to understand the reasons why these events of parasitism are so rare in the order Amblypygi.
\end{abstract}

Keywords: ectoparasitism, chigger mites

Mites (Acari) are commonly found in a wide variety of animals, both vertebrates and invertebrates. The relationship between mites and their hosts can be either phoretic, when intensity is low or infection has no cost to the host, or parasitic, with high negative costs to their hosts (Townsend et al. 2006). The negative impact of parasitic mites can be strong enough to result in the death of their hosts (Krantz 2009).

Ectoparasitic mites are commonly found associated with the majority of arachnids orders and this relationship has been more frequently studied in the orders Araneae, Scorpiones and Opiliones (see Welbourn and Young 1988, McCormick and Polis 1990, Cokendolpher 1993). Mites parasitising arachnids are mainly represented by the families Eutrombidiidae, Erythraeidae and Trombidiidae (see Welbourn and Young 1988, Armas and Trueba 2003, Townsend et al. 2006).

Few studies have investigated the association between ectoparasites and whip spider hosts (Weygoldt 2000, Armas and Trueba 2003). Weygoldt (2000) found fly larvae parasitising the whip spiders Acanthophrynus coronatus (Butler) (Phrynidae) and an unidentified species of the genus Phrynus Lamarck. Mites belonging to the genus Leptus Latreille (Erythraeidae) were reported parasitising Phrynus kennidae Armas et PérezGonzáles (Phrynidae - see Armas and Trueba 2003), and a new mite family (Mesostigmata: Reginacharllotiidae) has recently been discovered from Australia and Brazil (Walter 2013). Whereas the Australian species of the latter family was collected

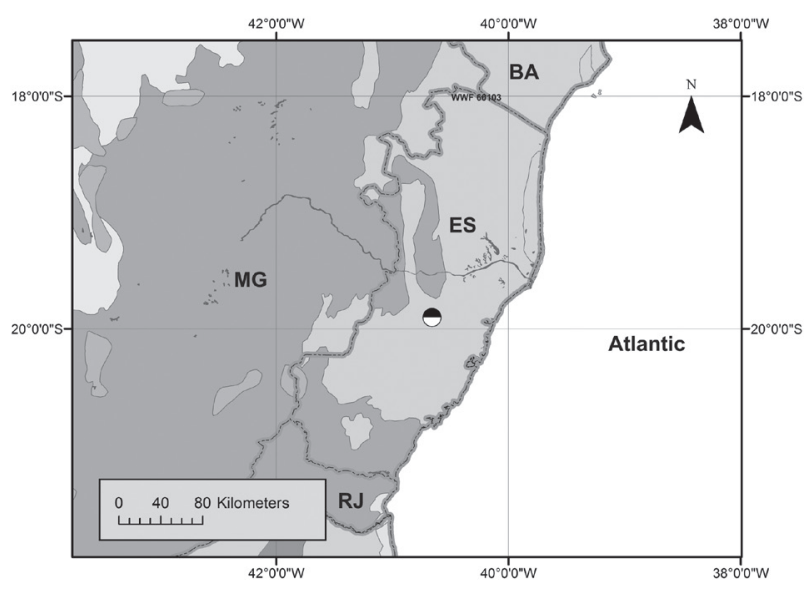

Fig. 1. Map showing the locality where the parasitized whip spider Charinus brasilianus was found (black and white circle). Abbreviations of Brazilian States: BA - Bahia; ES - Espírito Santo; MG - Minas Gerais; RJ - Rio de Janeiro.

from litter, the Brazilian species, Reginacharllotia braziliensis Walter, 2013, was found associated with Trichodamon froesi Mello-Leitão (Amblypygi: Phrynidae).

We sampled arachnids in a two ha Atlantic rainforest remnant at Nova Valsugana region, Santa Teresa, state of Espírito Santo, Brazil, in November 2005 (Fig. 1). This region is characterised by several small forest remnants surrounded by pasture used to rear livestock. The mites were identified to family with the aid of keys of Parasitengonina of Krantz and Walter (2009), and subsequently to the genus level using the key of Reed and Brennan (1975); Amblypygi identification followed the key proposed by Miranda and Giupponi (2011).

In addition, we inspected approximately 200 whip spider specimens from the families Phrynidae and Charinidae deposited in the arachnological collection of the Museu Nacional, Rio de Janeiro, Brazil (MNRJ), to search for further mite larvae. Photos were taken with a FujiFilm X10 attached to a Leica

Address for correspondence: T. Gonçalves-Souza, Instituto de Biologia, Departamento de Biologia Animal, Universidade Estadual de Campinas (UNICAMP), Rua Monteiro Lobato, Cidade Universitária, 13083-970, Campinas, SP, Brasil. Phone: +55 19 3521-6332;

E-mail: tgoncalves.souza@gmail.com 

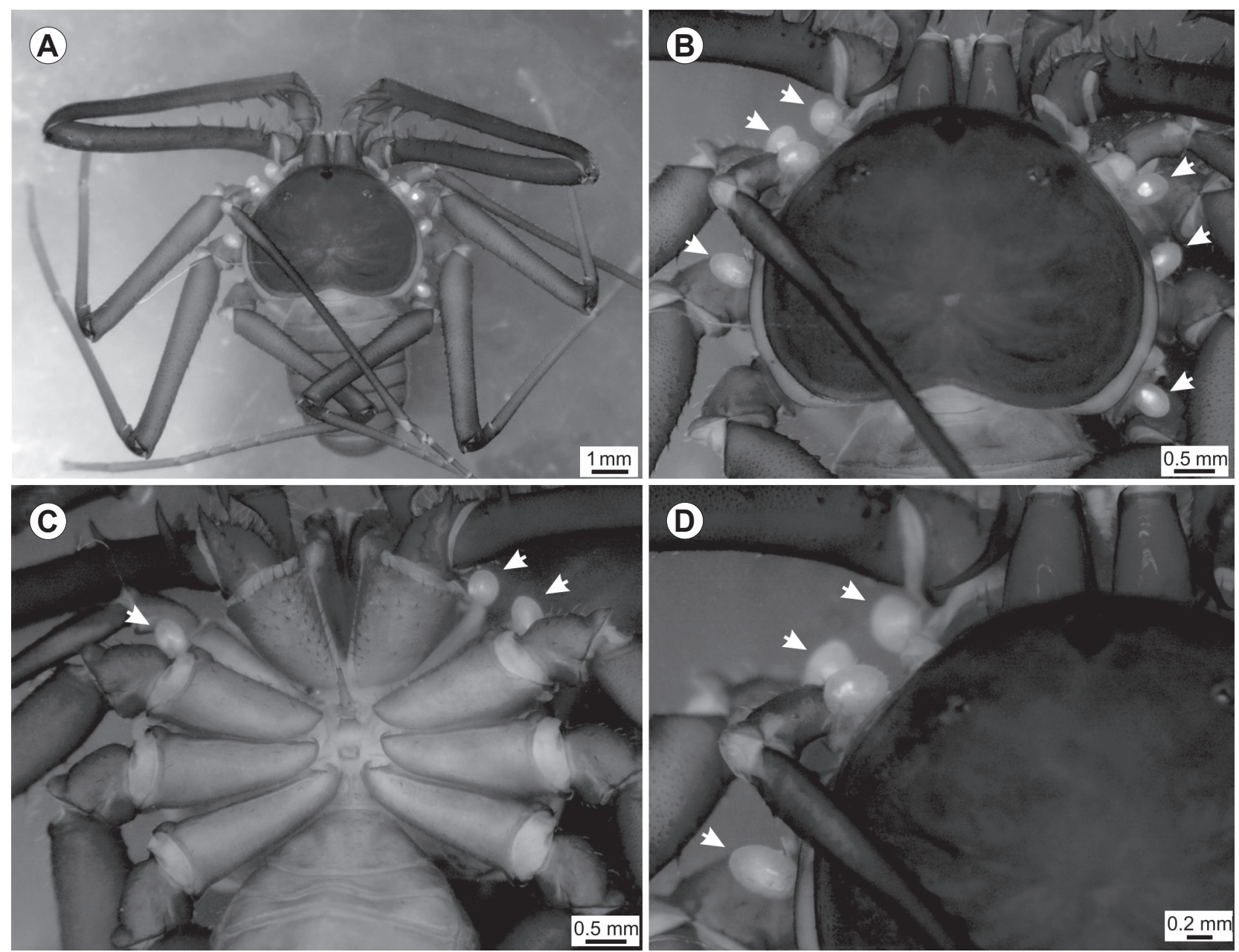

Fig. 2. Dorsal (A, B, D) and ventral (C) views of male Charinus brasilianus Weygoldt parasitized by larvae of Odontacarus sp. (Acari: Leeuwenhoekiidae) (arrows) on the intertegumental membrane of leg-prosoma joints.

MZ16 stereoscope. Scanning Electronic Microscopy (SEM) photos were obtained with a Jeol JSM-6390LV at microscope Centro de Microscopia Eletrônica de Varredura do Museu Nacional, Rio de Janeiro, Brazil.

The mite larvae were identified as Odontacarus sp. (Prostigmata: Leeuwenhoekiidae), which are ectoparasitic as larvae and free living as adults (Reed and Brennan 1975, Domrow 1991, Reeves et al. 2004). We found 12 mite larvae attached to the intersegmental membranes of the coxa-prosoma and trochantercoxa joints (Figs. 2, 3). These regions are lighter and softer than the hard sclerotized carapace of the prosoma and opisthosoma, favouring the attachment of these parasitic mites (McCormick and Polis 1990, Weygoldt 2000).

As far as we know, this is the first report of mites as ectoparasites of whip spiders of the family Charinidae (Amblypygi) and the first record of leeuwenhoekiid mites parasitising an invertebrate host. The few examples found in the literature of amblypygid parasitism can generate an intriguing question: why do ectoparasites occur less frequently on whip spiders than on other arachnids? One possible reason might simple be due to the scarceness of studies on these arachnids (e.g. Weygoldt 2000). They also might possess some adaptations that prevent them from being parasitized. In fact, we have not found a single parasitized whip spider among the nearly 200 examined specimens deposited at MNRJ, which would agree with the latter hypothesis. For instance, Weygoldt (2000) suggested that their highly sensitive and elongate first pair of legs (i.e. antenniform) might anticipate the presence of predator and thus explain the less frequent predation events suffered by whip spiders.

This report can trigger the interest of future works to test hypotheses concerning the occurrence of ectoparasites on whip spiders by comparing the rates of parasitism among co-occurring close relatives, such as spiders and harvestmen. This comparative approach could foster our understanding of the existence of lower rates of ectoparasitism in Amblypygi.

Ackonowledgements. We wish to thank P.R. Demite, R.J.F. Feres, R. Marques and D.B. Provete for feedback on earlier versions of this manuscript. The SEM micrographs were taken in the SEM Lab of Marine Diversity of the MNRJ (financed by PETROBRAS), with the kind assistance of Amanda Veiga. TG-S (2012/13912-5) and FAH (2011/50145-0, 2011/20805-8) were supported by FAPESP - São Paulo Research Foundation. 

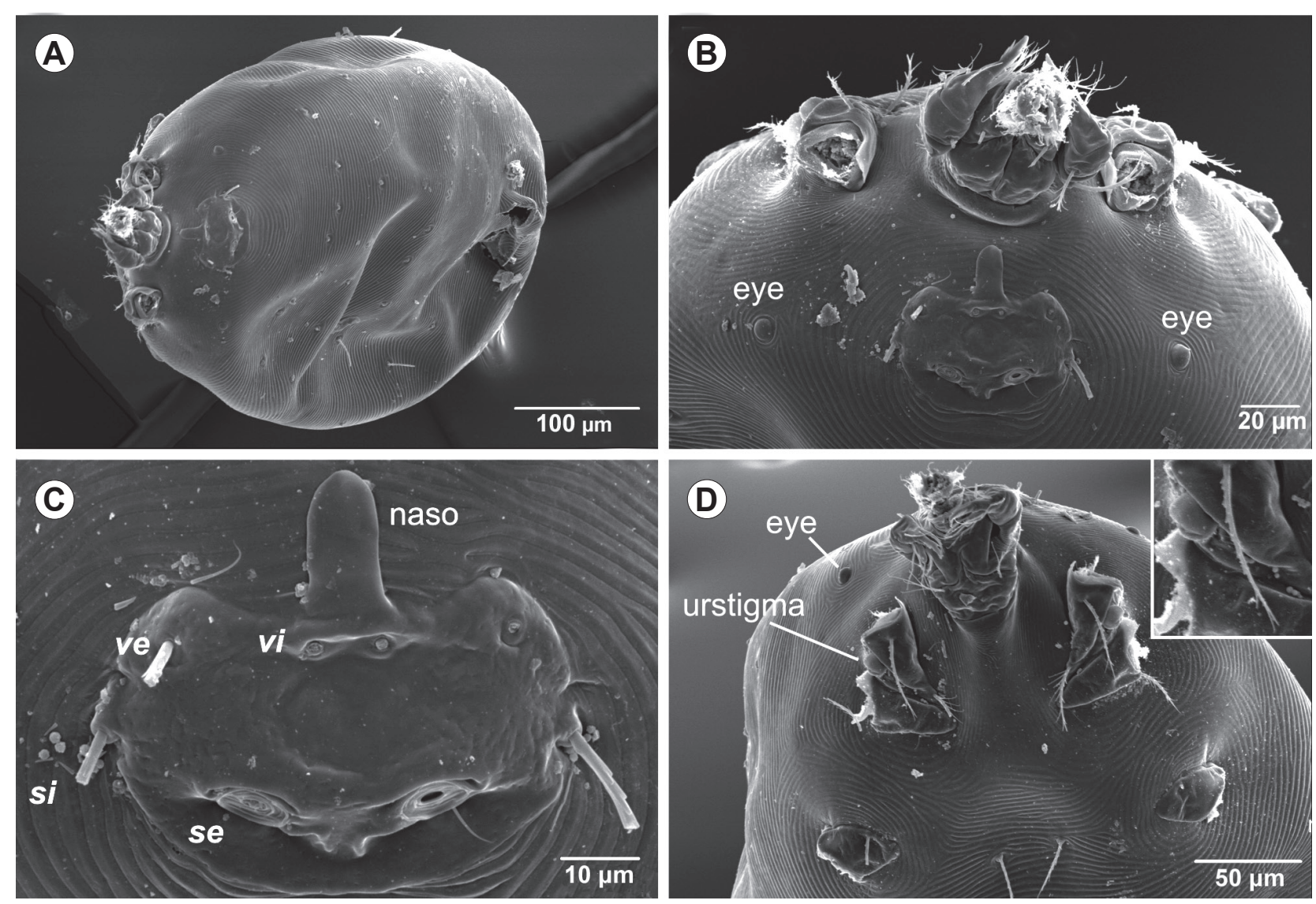

Fig. 3. Scanning electron micrographs of Odontacarus sp. (Acari: Leeuwenhoekiidae) from Charinus brasilianus Weygoldt (Amblypygi: Charinidae). A, B - dorsal view of the body with detached legs; $\mathbf{C}$ - detailed view of prodorsal plate (scutum) showing insertion of prodorsal setae; D - ventral view of prosoma (detailed view of urstigma). Abbreviations: ve - vertical external; $v i-$ vertical internal; se - scapular external; si - scapular internal.

\section{References}

Armas L.F., Trueba D.P. 2003: Primer registro de ácaros parasitos de amblipígidos (Arachnida: Amblypygi). Rev. Ibér. Aracnol. 7: 133-134.

Cokendolpher J.C. 1993: Pathogens and parasites of Opiliones (Arthropoda: Arachnida). J. Arachnol. 21: 120-146.

Domrow R. 1991: Acari (Prostigmata excluding Trombiculidae) parasitic on Australian vertebrates: an annotated checklist, keys and bibliography. Invertebr. Taxon. 4: 1283-1376.

Krantz G.W. 2009: Habits and habitats. In: G.W. Krantz and D.E. Walter (Eds.), A Manual of Acarology. Texas Tech University Press, Lubbock, Texas, pp. 64-82.

Krantz G.W., Walter D.E. 2009 (Eds.): A Manual of Acarology. Texas Tech University Press, Lubbock, Texas, 807 pp.

McCormick S.J., Polis G.A. 1990: Prey, predators, and parasites. In: G.A. Polis (Ed.), The Biology of Scorpions. Stanford University Press, Stanford, pp. 294-320.

Miranda G.S., Giupponi A.P.L. 2011: A new synanthropic species of Charinus Simon, 1892 from Brazilian Amazonia and notes on the genus (Arachnida: Amblypygi: Charinidae). Zootaxa 2980: 61-68.

Reed J.T., Brennan J.M. 1975: The subfamily Leeuwenhoekinae in the Neotropics (Acarina: Trombiculidae). Brigham Young Univ. Sci. Bull. 20: 1-42.

Reeves W.K., Durden L.A., Wrenn W.J. 2004: Ectoparasitic chiggers (Acari: Trombiculidae, Leeuwenhoekiidae), lice (Phthiraptera), and Hemiptera (Cimicidae and Reduviidae) from South Carolina, U.S.A. Zootaxa 647: 1-20.

Townsend V.R., Mulholland K.A., Bradford J.O., Proud D.N., Parent K.M. 2006: Seasonal variation in parasitism by Leptus mites (Acari, Erythraeidae) upon the harvestman, Leiobunum formosum (Opiliones, Sclerosomatidae). J. Arachnol. 34: 492-494.

Walter D.E. 2013: A new genus and family of sejine mites (Acari, Parasitiformes, Mesostigmata, Sejoidea) based on new species from Lord Howe Island and Brazil, and a redescription of Sejus americanus (Banks, 1902). Zootaxa 3691: 301-323.

Welbourn W.C., Young O.P. 1988: Mites as parasitic on spiders, with a description of a new species of Eutrombidium (Acari, Eutrombidiidae). J. Arachnol. 16: 373-385.

Weygoldt P. 2000: Whip Spiders (Chelicerata: Amblypygi): Their Biology, Morphology and Systematics. Apollo Books, Stenstrup, $163 \mathrm{pp}$.

Received 25 September 2013

Accepted 30 October 2013 